remember, however, that the type of case which is the most suitable is not the patient with the longstanding chronic lesion involving the greater part of one lung and a considerable part of the other, but the patient who is suffering from an acute lesion confined mainly to one lobe or even one lung and which does not rapidly respond and definitely improve under medical treatment.

\section{SOME POINTS IN THE DIAGNOSIS PULMONARY TUBERCULOSIS BY THE X RAYS. ${ }^{1}$}

By ALFRED C. JORDAN, M.D. Cantab., M.R.C.P. Lond., MEDICAL OFFICER IN CHARGE OF THE ROENTGEN RAY DEPARTMENT, ROYAL HOSPITAL FOR DISEASES OF THE CHEST.

IN the $\mathrm{X}$ ray examination of the chest for pulmonary tuberculosis the necessary observations fall into two groups: direct observations of the lungs and subsidiary observations. Taking the latter first, two points have been noted almost since the beginning of $X$ ray diagnosis - viz., the movements of the diaphragm and the size and positions of the heart. With regard to the diapliragm, deficient morement on one or both sides is admittedly a suggestive sign; it should always be noted, but care must be taken to avoid fallacies. Taken by itself deficient movement is no sign of disease of the lung; it may be due to an accidental cause-old basal pleurisy or paresis of the diaphragm if unilateral, while if bilateral it may be merely an individual peculiarity; many persons are able at will to breathe either with or without moving the diaphragm. A big firm abdomen may impede the morements of the diaphragm, rendering respiration purely thoracic.

With regard to the heart. for many years it has been held that in phthisis the heart is narrow and is placed vertically. The fact is that this type of heart occurs only in young adult phthisical sub. jects; it is not seen in children or in elderly persons, and not in advanced stages of the disease, for then the heart is dilated. The explanation of the narrow, rertical heart is simple: it is the heart of feeble, non-muscular young men and girls, who hare grown rapidly out of childhood. The mass of muscle being small, the left heart has not much work to do, consequently it does not attain the usual size. These feeble subjects are very apt to be attacked by tuberculosis; then the muscles waste, and the left ventricle, having less work than ever, becomes smaller still, and the heart becomes almost a symmetrical organ. The youths of this type who escape tuberculous infection grow more robust as the years pass, and the left heart grows stronger and becomes more prominent in the left chest.

Coming now to the direct evidences of tuberculous disease in the lungs, there is a sign usually quoted as the earliest evidence of the disease; this is a failure of the lung to "light up" on inspiration at one apex. In conjunction with deficient movement of the diaphragm this sign is said to be very suggestive (some say it is actually diagnostic) of a commencing lesion at that apex. Certainly this conjunction is worth noting when it occurs, but in my experience it is very rare, and a "failure of an apex to light up" is very difficult to make out with certainty; there are endless fallacies, due to the position of the $X$ ray tube, the thickness of the pectoral muscles of the patient, the "lie" of the ribs and clavicle, \&c., and at best it is almost ${ }^{1}$ A lecture delivered at the Royal Hospital for Diseases of the Chest on March 6th. impossible to reproduce this "failure" on a photographic plate with any certainty. I am quite sure that we should diagnose pulmonary tuberculosis in a large number of healthy subjects if we were to rely on this sign. In my experience the only trustworthy sign of tuberculous disease in the lungs is mottling. This brings me to an important section of the subject.

The rational diagnosis of early pulmonary tuberculosis has been kept back many years by the teaching, founded on stethoscope observation, that the disease commences at the apex. X ray observations have made the fact increasingly obvious that this is not the case; it is quite rare to find tuberculous mottling limited to an apex, and when there is apical mottling there is nearly always mottling in the lung between the root and the apex, and also mottling disposed radially from the root along the air tubes toward the periphery.

To understand the mode of infection of the lungs it is necessary to study the $X$ ray appearances of the healthy lungs; I took up this study three years ago and published my results in two papers. ${ }^{2}$ The work may be summed up as follows. All healthy lungs show certain blotches at the roots and linear shadows radiating from the roots. By direct dissection of post-mortem specimens of healthy lungs under the fluorescent screen it may easily be shown that the blotches consist of enlarged lymphatic glands, usually containing calcareous deposit, while the linear shadows are due to fibrous tissue surrounding the cartilages of the air tubes. 'These changes are the end-results of the invasion of tubercle bacilli. In some cases earlier stages were shown in sections near the roots of these "healthy" lungs. The air tubes were full of catarrhal cells (epithelioid plates), and there were collections of lymphocytes around the cartilages. These specimens were indistinguishable from sections showing the most chronic forms of pulmonary tuberculosis. They were, in fact, sections of this disease, though the patients had no signs or symptoms of it, and probably would never have shown signs had they lived. Thus it appears that all of us have to deal with tubercle bacilli, and show changes due to our victorious fight.

The further study showed the usual manner in which the invasion takes place in cases of progressing tuberculous disease of the lungs. Many continental writers have lately drawn attention to the enlarged glands at the roots in cases of early pulmonary tuberculosis, and have come to the conclusion that these glands are the starting-point of the disease. This view seems to me illogical. Take the parallel case of a tuberculous finger with a mass of tuberculous glands in the axilla; nobody would argue that the disease had spread from the glands to the finger. The lymphatic glands at the roots of the lungs are the filters for invading microbes just as in other parts of the body; the glandular infection is secondary. True, these glands may break down and so become centres of infection, but such an occurrence is accidental and has no relation to the usual course of events in phthisis; as an early accident it occurs most often in children.

What, then, is the usual mode of invasion of the lungs? The first change is a catarrh of the large air tubes; the lumen of the tubes fills with epithelioid cells. The catarrh may extend to the smaller tubes, and there may be sputum in which a few tubercle bacilli may be found by studious search. ${ }_{2}$ Peribronchial Phthisis, Practitioner, February, 1912, and Brit. Med. Jour., August 31st, 1912. 
$\mathrm{Up}$ to this stage there are no $\mathrm{X}$ ray changes in the lungs ; the disease is practically a bronchitis. The next stage, however, is the most important of all; tubercle bacilli (accompanied by other microbes, as a rule) pass through the walls of the air tubes, and lead to the appearance of groups of leucocytes in the connective tissue surrounding the bronchial cartilages. This peribronchial infiltration is readily visible with the $X$ rays; it gives rise to the fine mottling which is characteristic of early tuberculous disease of the lungs. The distribution of this mottling is always a radial one from the root, though from the first the mottling may radiate out to the periphery of the lung and up to the level of the clavicle. The distinctive feature of the mottling is its peribronchial arrangement along the branching system of air tubes. While this mottling is appearing the glands at the root are fulfilling their normal function; the root shadows increase in size. This condition I have named "peribronchial phthisis"; undoubtedly it is the usual mode of onset of pulmonary tuberculosis. Under suitable conditions a cure may occur, the leucocytes disappearing, and their place taken by new fibrous tissue. On $\mathrm{X}$ ray examination there would then be no mottling, but an increase in the thickness of the radiating lines around the air tubes. In unfavourable cases the leucocytic invasion of the tissues goes on, the individual "mottles" coalesce to form blotches, the disease reaches the apex (by way of the air tubes), and soon gets a firm hold in this, the most vulnerable region of the lungs. The physician, relying on his stethoscope to inform him as to the extent of the disease, can detect no signs (except perhaps those due to bronchial catarrh) until the infiltration is approaching the apex; early peribronchial phthisis gives no physical signs of its presence. By this time the disease is well advanced, and the most favourable early stages have slipped by.

There is no need to repeat the evidence and arguments of my former papers on this subject; I have only to say that recent experience has fully confirmed them, and has, in my opinion, placed beyond doubt the fact that the usual mode of onset of pulmonary tuberculosis is that which occurs in peribronchial phthisis. The cases in which the mottling is confined to one or both apices are rare, and even such cases can be shown to have arisen in the same way, the intermediate portions of lung having healed, while the more vulnerable apex has succumbed. The continuity of the process from root to apex can always be demonstrated.

Upper Wimpole-street, W.

\section{A CASE OF THORACIC ANEURYSM OF UNUSUAL SIZE.}

BY GEORGE COOPER, B.A. R.U.I., M.D. BELF., LATE RESIDENT MEDICAI OFFICER, GENERAL INFIRMARY, WORCESTER.

THE following notes of a case of thoracic aneurysm, admitted to the Worcester General Infirmary on Jan. 8th, 1913, may prove of interest on account of the unusual size of the tumour and of the fact that the patient, aged 60 years, continued at his usual occupation until a few days before admission, although the swelling even then was of the size seen in the accompanying illustra. tion, which was taken shortly after his being admitted to the infirmary.

The history of the onset of the illness presented no unusual features. Towards the end of March, 1912, the patient experienced at first a tingling pain in the chest and back, extending to the right arm. The pain, at first intermittent, soon became con. tinuous, and in the course of a few weeks a hacking cough and a certain amount of dyspncea added to his discomfort. About a month after the onset of these symptoms he noticed a small pulsating swelling in the second right intercostal space. Within a few weeks it had grown to the size of an orange, and it continued to increase steadily in size until at the end of nine months it had attained the enormous dimensions seen in the illustration. The increasing pain, cough, and dyspnoea kept pace with the growth of the tumour, but in spite of the distress he must have endured, the patient, as already stated, had remained at work until a few days before admission to the infirmary. There was no history or evidence of syphilis.

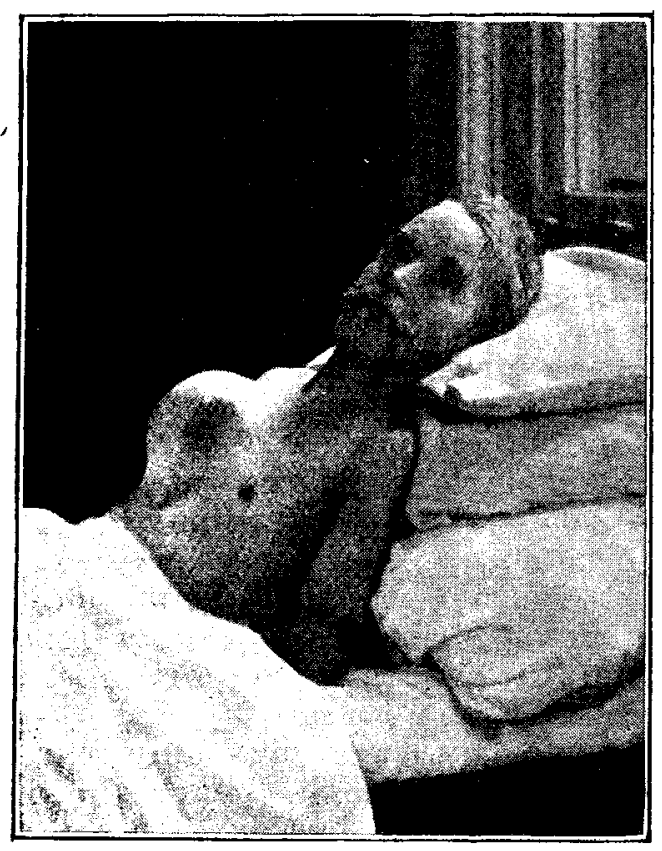

On examination the man was found to be very cachectic and considerably wasted. Dyspncea was marked, and the slightest morement caused him intense pain. The pulse was 96, regular, and synchronous in both radials. The blood pressure taken on the right arm was 104 and 108 on the left arm. The right pupil was slightly dilated and reacted somewhat sluggishly to light and accommodation. The tracheal tug could only be faintly elicited. The voice was husky, the right vocal cord being paralysed, and the characteristic brassy cough was present. The right arm was somewhat cdematous, but the right side of the face and neck were only slightly affected. A huge swelling, tense and pulsating and dull on percussion, protruded from the right side of the chest wall in front. It was globular in shape and had the follow. ing measurements: $22 \frac{1}{4}$ inches round the base, 9 inches from the upper pole of the tumour to the lower pole across the most prominent part, and $11 \frac{1}{2}$ inches measured right to left across the tumour. The heart appeared to be of normal size, and the apex beat could be made out in the fifth left inter. costal space $1 \frac{1}{2}$ inches inside the nipple line. The pulsations of the tumour were expansile, somewhat forcible in character, and synchronous with the heart beat. Auscultation of the heart revealed a soft systolic murmur at the apex, but otherwise the heart sounds were normal. Over the tumour the heart sounds were well conducted, but the absence of a systolic bruit and "ringing" second sound were noteworthy features. The breath sounds were almost completely lost over the entire right side of 